\title{
Adult intussusceptions caused by a lipoma in the jejunum: report of a case and review of the literature
}

Ouadii Mouaqit ${ }^{\text {* }}$, Hafid Hasnai ${ }^{1}$, Leila Chbani ${ }^{2}$, Bachir Benjelloun ${ }^{1}$, Hicham El Bouhaddouti ${ }^{1}$, Karim Ibn el Majdoub', Imane Toughrai', Said Ait Laalim', Abdelmalek Oussaden' ', Khalid Maazaz', Afaf Amarti $^{2}$ and Khalid Ait Taleb ${ }^{1}$

\begin{abstract}
Intussusceptions in adults is rare. Gastrointestinal lipomas are rare benign tumors and intussusceptions due to a gastrointestinal lipoma constitutes an infrequent clinical entity. Lipoma may develop as a benign tumor in all organs and rarely in large or small intestine. The present report describes a case of jejunojejunal intussusceptions in an adult with a history of colicky upper abdominal pain. lleo-ileal invagination was diagnosed by computed tomography scan. Exploratory laparotomy revealed jejunojejunal intussusceptions secondary to a lipoma which was successfully treated with segmental intestinal resection. A review of the literature is also performed regarding this rare association revealing the diagnostic and therapeutic debates that exist.
\end{abstract}

\begin{abstract}
(french)
L'invagination chez les adultes est rare. Les lipomes gastro-intestinaux sont de rares tumeurs bénignes et l'invagination intestinale due à un lipome gastro-intestinal constitue une entité clinique trés rare. Le lipome peut se développer comme une tumeur bénigne dans tous les organes et rarement dans l'intestin grêle ou le colon. Le présent rapport décrit un cas d'invagination jéjunojéjunale chez un adulte avec une histoire de douleurs abdominales. Iléo-iléale invagination a été diagnostiquée par tomodensitométrie. Une laparotomie exploratrice a révélé l'existence d'une invagination jéjunojéjunale secondaire à un lipome qui a été traitée avec succès par une résection intestinale segmentaire. Une revue de la littérature est également effectuée au sujet de cette association rare révélant les débats diagnostiques et thérapeutiques qui existent.
\end{abstract}

Keywords: Intussusceptions, Jéjunal lipoma, Intestinal tumor, Surgery

\section{Background}

Intussusceptions was reported for the first time in 1674 by Barbette of Amsterdam [1]. The occurrence of intussusceptions in adults is rare, accounting for less than $5 \%$ of all cases of intussusceptions and almost 1\%-5\% of bowel obstruction [2]. In contrast to pediatric intussusceptions, which is idiopathic in $90 \%$ of cases, adult intussusceptions has an organic lesion in $70 \%$ to $90 \%$ of cases [3]. The majority of lipomas in the small bowel are

\footnotetext{
* Correspondence: mouaqit1975@hotmail.com

'Surgery Department, University Hospital Hassan II, Fez 30000, Morocco Full list of author information is available at the end of the article
}

solitary. Approximately 5\% are multiple [4]. Symptomatic lipoma manifestations are hemorrhage or intestinal obstruction. Due to their intramural location, lipomas can also serve as the leading point for intussusceptions. We report a rare case of jejuno-jejunal intussusceptions in an adult secondary to an jejunal lipoma.

\section{Case presentation}

A 35-year-old man was admitted to the emergency department in a tertiary referral hospital with 4 months history of intermittent upper abdominal pain accompanied with nausea. The patient had no past history of peptic ulcer disease, alteration in bowel habits, melena or

\section{Ciomed Central}


weight loss. On examination, he was apyrexial and hemodynamically stable. His abdomen was distended and no palpable abdominal masses; bowel sounds were hyper audible. Initial A rectal examination revealed no masses or blood. Laboratory blood tests were normal. Abdominal radiography revealed prominent dilatation of the small bowel with air fluid levels (Figure 1). Abdominal CT showed a target sign- or sausage-shaped lesion typical of an intussusceptions that varied in appearance relative to the slice axis (Figure 2). The inner central area represented the invigilated intussuscepted, surrounded by its mesenteric fat and associated vasculature, and all surrounded by the thick-walled intussuscipiens. More head-side scans showed a low-density homogenous mass measuring $4 \mathrm{~cm}$ that was considered to be the leading point for the invagination (Figure 3). These findings led to a diagnosis of intussusceptions induced by a tumor most likely begin. The decision was made to undertake an urgent exploratory laparotomy. At laparotomy, $50 \mathrm{~cm}$ distal to the ligament of Treitz, a jejuno-jejunal intussusceptions was identified. We conducted a desinvagination Benin saw the character of the lesion on CT. The presence of irreversible ischemia in a small portion of the intussusceptum necessitated segmental resection and primary anastomosis (Figure 4). The postoperative period was uneventful and the patient was discharged on the sixth postoperative day. Gross examination of the respected specimen revealed a round tumor covered with mucosa measuring $6 \mathrm{~cm}$. A microscopic examination revealed fat cells proliferating in the submucosal layer and confirmed the diagnosis of ileal lipoma (Figure 5).

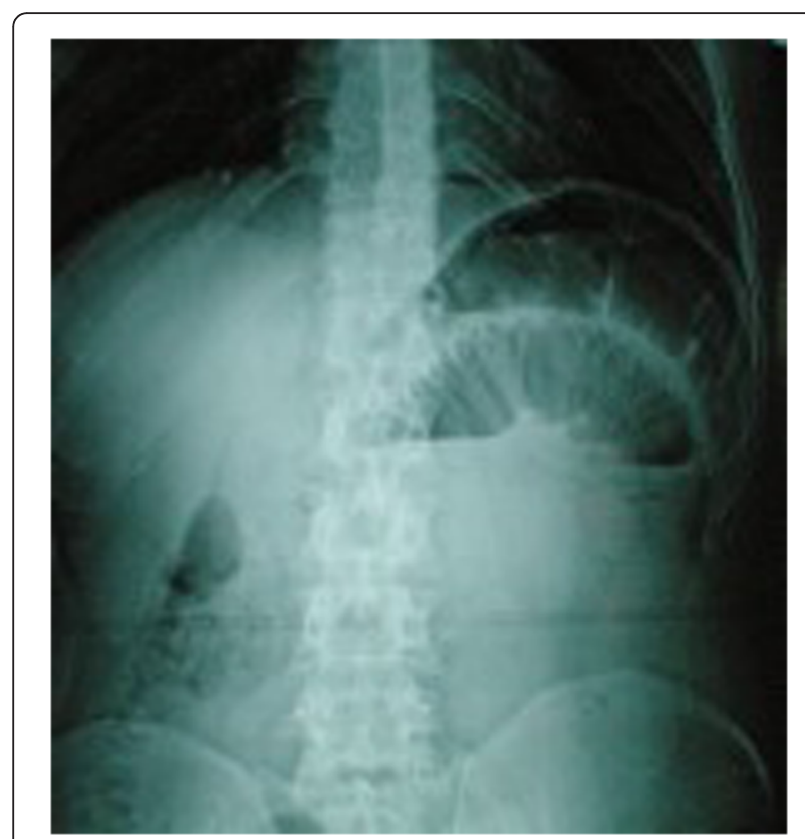

Figure 1 Abdominal X-Ray. In favor of bowel obstruction.

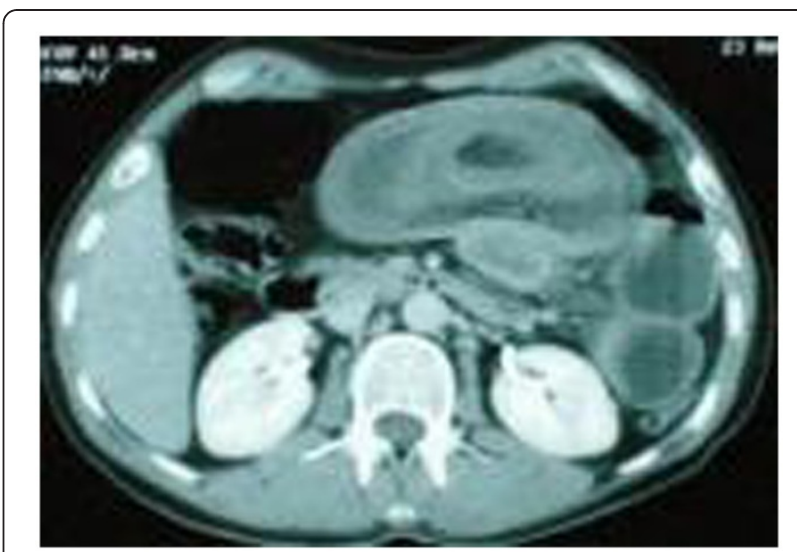

Figure 2 Abdominal computed tomography. Showing a fatty oval mass in the small intestine.

The histopathology report confirmed a $60-\mathrm{mm}$ submucosal lipoma in the jejunum as a cause for a $30-\mathrm{cm}$ jejuno-jejunal intussusceptions. There was no evidence of dysplasia or malignancy.

\section{Discussion}

Intussusceptions in adulthood is unusual, with an incidence of approximately 2-3 cases per population of

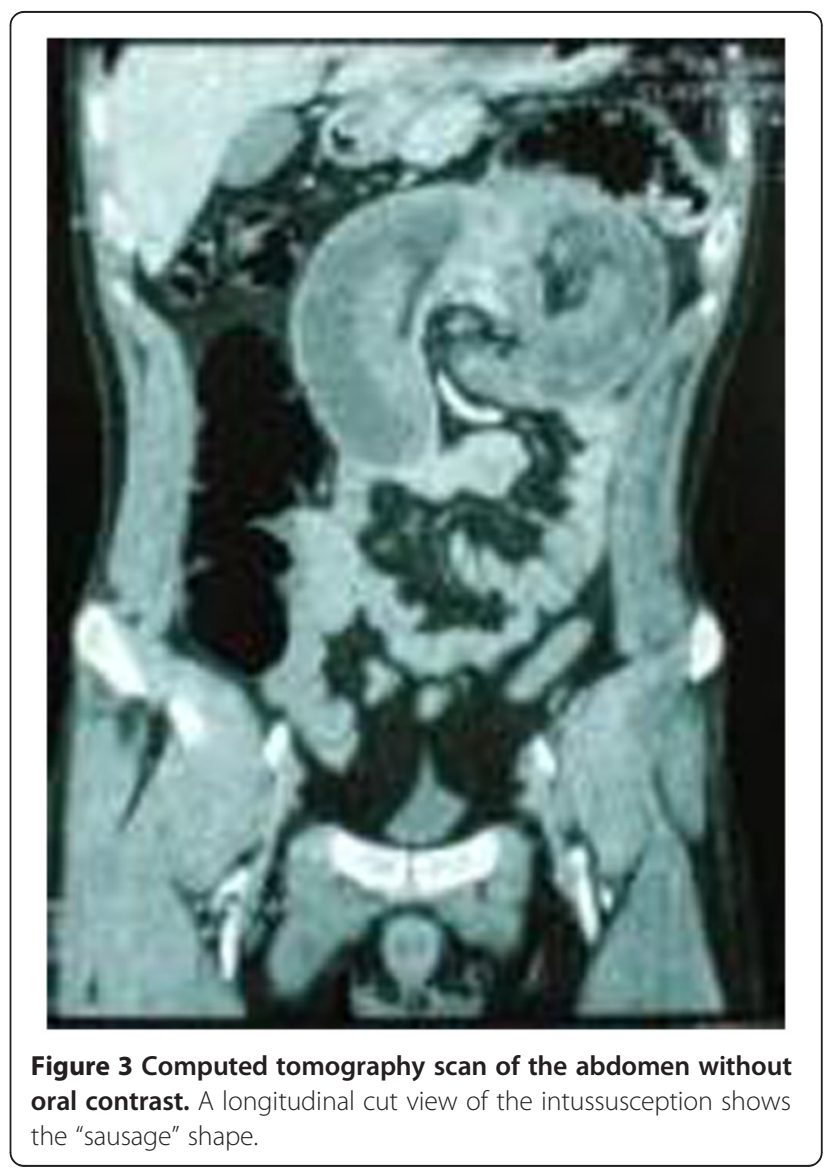




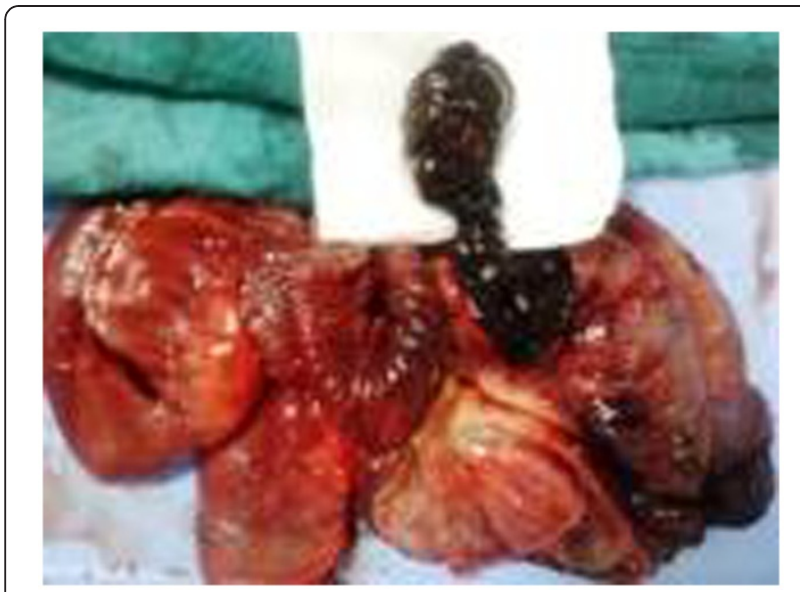

Figure 4 Intraoperative findings of the lipoma: A pedunculated lesion, measuring $60 \mathrm{~mm}$, was the lead point of the intussusception.

1000000 per year [5]. The most common classification system divides intussusceptions into four categories: enteric, ileocolic, ileocaecal and colonic [1-4]. In adults, intussusceptions is more likely to present insidiously with vague abdominal symptoms and rarely presents with the classic triad of vomiting, abdominal pain and passage of blood per rectum, making diagnosis difficult [6]. Tumors of the small bowel account for only $1 \%$ to $2 \%$ of all gastrointestinal tumors, and benign tumors account for approximately $30 \%$ of all small-bowel tumors [7]. Lipomas are benign tumors of mesenchymal origin. They are the second most common benign tumors in the small intestine and account for $10 \%$ of all benign gastrointestinal tumors and $5 \%$ of all gastrointestinal tumors $[1,2,5]$. Gastrointestinal lipomas are most commonly located in the colon (65\% to $75 \%$ ), small bowel

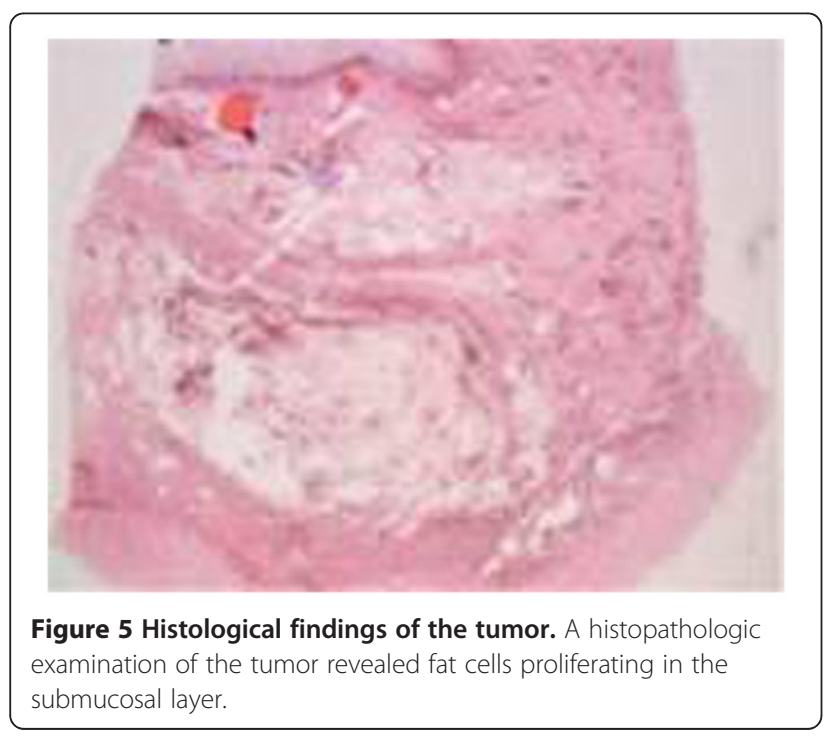

(20\% to $25 \%)$ and occasionally in the foregut $(<5 \%)[8]$. Fifty-one cases of adult intussusceptions induced by a lipoma, including our present case, have been reported in the English literature during the past decade (Table 1) [9]. Lipomas are largely asymptomatic. The majority of presenting features are either intestinal obstruction or hemorrhage [1,2,5-8]. Their usual location in the small intestine is ileum (50\%) while jejunum is the least common. The peak age of incidence is in the 6th-7th decades of life and it appears that females are more prone to lipomas. Malignant degeneration has never been reported [5]. The clinical presentation is very nonspecific which makes this a difficult condition to diagnose. According to the literature, only $32 \%$ to $50 \%$ of cases are diagnosed preoperatively, despite the evolution of imaging methods [9-11]. Abdominal pain, nausea, diarrhea and bleeding per rectum are the common symptoms. Rarely, this can present with acute intestinal obstruction. The classical triad of abdominal pain, sausage shaped palpable mass and passage of red current jelly stools seen in children is rarely seen in adults. Fewer than $20 \%$ of cases present acutely with complete bowel obstruction. A palpable abdominal mass is present in only $7 \%$ to $42 \%$ of cases [12,13]. Lipomas can be diagnosed through conventional endoscopy, capsule endoscopy, barium studies and, most importantly, CT scan [14]. Ultrasound is usually the first modality to be recruited. However, it is operator-dependent and the presence of distended bowel decreases the ability to demonstrate the site of the obstruction. Computed tomography is the imaging method of choice for diagnosing intussusceptions. A submucosal lipoma can be diagnosed if a smooth well-circumscribed mass of fat density (-50 to -100 Hounsfield Units) is revealed within the lumen of the bowel or intussuscipiens. The sensitivity of $\mathrm{CT}$ scan to correctly diagnose intussusceptions has been reported from 71.4\%-87.5\% while its specificity in adults has been reported to be $100 \%$ as verified by the subsequent surgery $[14,15]$. Capsule endoscopy and digital balloon endoscopy are newer means for diagnosing lipomas and are particularly helpful in cases involving small bowel lipomas [8]. Definitive surgical resection remains the recommended treatment for adult intussusceptions due to the large proportion of structural causes and the relatively high incidence of malignancy; however, the optimal surgical management remains controversial $[1,2,6,7,9]$. Some investigators have stated that small bowel intussusceptions should still be reduced only in patients in whom a definitive benign diagnosis has been made preoperatively, or in patients in whom resection may result in short gut syndrome [9]. The dangers of transperitoneal, vascular, and intraluminal seeding after exposing and handling friable and edematous malignant tissues has led many surgeons to 
Table 1 The characteristics of the reported cases of adult intussusception induced by a lipoma

\begin{tabular}{|c|c|c|c|c|c|c|}
\hline Case & Age & Gender & Diagnostic modality & Tumor location & Size $(\mathrm{cm})$ & Reference \\
\hline 1 & 69 & Male & US, CS & Descending colon & 4 & J Clin Ultrasound \\
\hline 2 & 42 & Male & $\mathrm{CS}, \mathrm{BE}, \mathrm{CT}$ & Descending colon & 4.5 & Am Surg \\
\hline 3 & 39 & Male & US, CT & Ileum & 4 & J Korean Med Sci \\
\hline 4 & 72 & Male & EGD, US, CT & Stomach & 10 & Dig Surg \\
\hline 5 & 28 & Male & $C T$ & Jejunum & 3 & Ann R Coll Surg Engl \\
\hline 6 & 20 & Female & $\mathrm{CT}$ & Ileum & 18 & Emerg Radiol \\
\hline 7 & 41 & Male & $\mathrm{CT}$ & Ileum & ND & Australas Radiol \\
\hline 8 & 44 & Female & $C T, C S, E C S$ & Ileum & 5 & Abdom Imaging \\
\hline 9 & 51 & Female & US, ECS, CT & Cecum & 10 & Rom J Gastroenterol \\
\hline 10 & 56 & Male & US, CT & Ascending colon & 6 & J Laparoendosc Adv Surg Tech A \\
\hline 11 & 50 & Male & $\mathrm{ECS}, \mathrm{CS}, \mathrm{CT}$ & Ascending colon & 5 & Pathol Int \\
\hline 12 & 72 & Male & $C T, E G D$ & Stomach & 6 & Can J Gastroenterol \\
\hline 13 & 55 & Male & $C T$ & Ileum & ND & Surg Today \\
\hline 14 & 63 & Female & US, CT & Ileum & 2.5 & Surg Today \\
\hline 15 & 73 & Female & ECS, MRI & Sigmoid colon & ND & Arch Surg \\
\hline 16 & 63 & Male & $\mathrm{CT}$ & Ileum & 3 & JSLS \\
\hline 17 & 85 & Male & US, CT & Jejunum & 4 & J Gastroenterol Hepatol \\
\hline 18 & 62 & Male & $C T, C S$ & Sigmoid colon & 3.5 & Dig Dis Sci \\
\hline 19 & 55 & Female & $\mathrm{CT}$ & Transverse colon & 12 & Am Surg \\
\hline 20 & 31 & Female & $C T$ & Ascending colon & 5 & Can J Surg \\
\hline 21 & 47 & Female & US, CT & Ileum & 5 & Ulus Travma Acil Cerrahi Derg \\
\hline 22 & 56 & Female & US, CS, CT & Transverse colon & 5 & Ulus Travma Acil Cerrahi Derg \\
\hline 23 & 64 & Male & $\mathrm{CS}, \mathrm{CT}$ & Transverse colon & 6 & Clin Gastroenterol Hepatol \\
\hline 24 & 55 & Male & $C T, E C S$ & Jejunum & 4 & World I Gastroenterol \\
\hline 25 & 42 & Male & US, CT & Ileum & 3 & Case Rep Gastroenterol \\
\hline 26 & 47 & Female & $\mathrm{CT}$ & Ileum & 3 & J Laparoendosc Adv Surg Tech \\
\hline 27 & 47 & Female & $C T, C S$, Enema & Ascending colon & 5 & Endoscopy \\
\hline 28 & 36 & Male & $\mathrm{CS}, \mathrm{CT}, \mathrm{ECS}$ & Ileum & 9 & Cases J \\
\hline 29 & 36 & Male & $C T, E C S$ & Ileum & 4 & J Nippon Med Sch \\
\hline 30 & 82 & Male & $\mathrm{CS}, \mathrm{CT}$ & Sigmoid colon & 8 & Gastrointest Endosc \\
\hline 31 & 69 & Male & $C T, C S$ & Transverse colon & 7 & Dig Dis Sci \\
\hline 32 & 38 & Female & $\mathrm{CS}, \mathrm{CT}$ & Ileum & 3.3 & Clin Gastroenterol Hepatol \\
\hline 33 & 38 & Female & US, CT, CS & Cecum & 6 & Emerg Radiol \\
\hline 34 & 45 & Male & $C T$ & Ileum & 2.5 & N Engl J Med \\
\hline 35 & 43 & Female & $\mathrm{CS}, \mathrm{CT}$ & Ascending colon & 5 & Rev Esp Enferm Dig \\
\hline 36 & 57 & Female & $\mathrm{CS}, \mathrm{CT}$ & Transverse colon & 5.5 & Rev Esp Enferm Dig \\
\hline 37 & 51 & Male & US, CT, CS & Ileum & 3 & Gastroenterology \\
\hline 38 & 77 & Male & $\mathrm{CT}$ & Cecum & 3.5 & JSLS \\
\hline 39 & 46 & Male & $\mathrm{CS}, \mathrm{CT}, \mathrm{ECS}$ & Descending colon & 6 & Endoscopy \\
\hline 40 & 33 & Male & $C T, C S, B E$ & Ileum & 4 & Case Rep Gastroenterol \\
\hline 41 & 32 & Female & $\mathrm{CT}$ & Ascending colon & 5.8 & Gastroenterology \\
\hline 42 & 49 & Male & US, CT & Descending colon & 5 & Gastroenterology \\
\hline 43 & 53 & Female & US, CS, ECS & Ascending colon & 7 & Medicina (Kaunas) \\
\hline 44 & 26 & Female & $C T$ & Ileum & ND & Am J Surg \\
\hline 45 & 51 & Female & $\mathrm{CT}$ & Transverse colon & 6.2 & J Gastroenterol Hepatol \\
\hline 46 & 68 & Male & CS & Jejunum & 3.2 & World J Gastroenterol \\
\hline
\end{tabular}


Table 1 The characteristics of the reported cases of adult intussusception induced by a lipoma (Continued)

\begin{tabular}{lllllll}
\hline 47 & 52 & Female & CT & lleum & 3.2 & J Med Case Reports \\
\hline 48 & 62 & Female & US & lleum & 7 & J Clin Ultrasound \\
\hline 49 & 65 & Male & CT & lleum & 1.2 & World J Gastrointest Surg \\
\hline 50 & 68 & Female & US, CT, ECS & lleum & 1.5 & Surg Today \\
\hline 51 & 35 & Male & CT & jejunum & 6 & \\
\hline
\end{tabular}

advocate en bloc resection of the lesion. All surgeons agree, though, that reduction should not be attempted if there are signs of irreversible bowel ischemia, inflammation or when malignancy is being suspected $[5,16,17]$. The advantages of intraoperative reduction of the intussusceptions prior to resection, especially when the small bowel is affected, are that it may preserve a considerable length of bowel and thereby prevent development of short-bowel syndrome.

\section{Conclusion}

The lipoma is a rare benign tumor of the digestive tract. The diagnosis of intussusceptions in adults can be difficult because of atypical and episodic symptoms. A high level of clinical suspicion and an abdominal CT scan are most useful tools for making a timely diagnosis. Surgical resection remains the treatment of choice and produces an excellent prognosis.

\section{Consent}

Written informed consent was obtained from the patient for publication of this case report and accompanying images

\section{Abbreviations \\ CT: Computed tomography; MRI: Magnetic resonance imaging; \\ CS: Colonoscopy; ECS: Enema contrast study; \\ EGD: Esophagogastroduodenoscopy; US: Ultrasonography; ND: Not described.}

\section{Competing interests}

The authors declare that they have no competing interests.

\section{Authors' contributions}

All of the authors were involved in the preparation of this manuscript. OM performed the operation and revised the manuscript. HH was an assistant surgeon and made substantial contributions to conception and design. LC described histological finding and was involved in drafting the manuscript. All authors read and approved the final manuscript.

\section{Author details}

${ }^{1}$ Surgery Department, University Hospital Hassan II, Fez 30000, Morocco. ${ }^{2}$ Department of pathology, University Hospital Hassan II, Fez 30000, Morocco.

Received: 12 April 2012 Accepted: 16 August 2012

Published: 22 August 2012

\section{References}

1. Krasniqi AS, Hamza AR, Salihu LM, Spahija GS, Bicaj BX, Krasniqi SA, et al: Compound double ileoileal and ileocecocolic intussusception caused by lipoma of the ileum in an adult patient: A case report. J Med Case Reports 2011, 5(1):452
2. Balamoun H, Doughan S: lleal lipoma. A rare cause of ileocolic intussusception in adults: Case report and literature review. World J Gastrointest Surg 2011, 3(1):13-15.

3. Balik AA, Ozturk G, Aydinli B, Alper F, Gumus H, Yildirgan Ml, et al: Intussusception in adults. Acta Chir Belg 2006, 106:409-412.

4. Atila K, Terzi C, Obuz F, Yilmaz T, Füzün M: Symptomatic intestinal lipomas requiring surgical interventions secondary to ileal intussusception and colonic obstruction: report of two cases. Ulus Travma Acil Cerrahi Derg 2007, 13:227-231.

5. Andreas M, Lagoudianakis EE, Dimitrios D, Tsekouras DK, Markogiannakis $H$, Genetzakis M, et al: Lipoma induced jejunojejunal intussusceptions. World J Gastroenterol 2007, 13(26):3641-3644.

6. Ali A, Morteza N, Rasoul M, Bodaghabadi M, Mardany O, Ali FA, et al: lleal intussusception secondary to both lipoma and angiolipoma. A case report Cases J 2009, 2:7099.

7. Akagi I, Miyashita M, Hashimoto M, Makino H, Nomura T, Tajiri T: Adult intussusception caused by an intestinal lipoma: report of a case. J Nihon Med Sch 2008, 75(3):166-170.

8. Chou JW, Feng CL, Lai HC, Tsai CC, Chen SH, Hsu CH, et al: Obscure gastrointestinal bleeding caused by small bowel lipoma. Intern Med 2008, 47:1601-1603.

9. Namikawa T, Hokimoto N, Okabayashi T, Kumon M, Kobayashi M, Hanazaki K: Adult ileoileal intussusception induced by an ileal lipoma diagnosed preoperatively: report of a case and review of the literature. Surg Today 2012, 42(7):686-692.

10. Barussaud M, Regenet N, Briennon X, de Kerviler B, Pessaux P, KohnehSharhi $\mathrm{N}$, et al: Clinical spectrum and surgical approach of adult intussusceptions: a multicentric study. Int I Colorectal Dis 2006, 21:834-839

11. Haas EM, Etter EL, Ellis S, Taylor TV: Adult intussusception. Am J Surg 2003, 186(1):75-76.

12. Thompson WM: Imaging and findings of lipomas of the gastrointestinal tract. AJR Am J Roentgenol 2005, 184:1163-1171.

13. Huang BY, Warshauer DM: Adult intussusception: diagnosis and clinical relevance. Radiol Clin North Am 2003, 41:1137-1151.

14. Kuzmich S, Connelly JP, Howlett DC, Kuzmich T, Basit R, Doctor C lleocolocolic intussusception secondary to a submucosal lipoma: an unusual cause of intermittent abdominal pain in a 62-year-old woman. J Clin Ultrasound 2010, 38(1):48-51.

15. Barbiera F, Cusma S, Di Giacomo D, et al: Adult intestinal intussusception: comparison between $\mathrm{CT}$ features and surgical findings. Radiol Med (Torino) 2001, 102:37-42.

16. Hadithi M, Heine GD, Jacobs MA, van Bodegraven AA, Mulder CJ: A prospective study comparing video capsule endoscopy with doubleballoon enteroscopy in patients with obscure gastrointestinal bleeding. Am J Gastroenterol 2006, 101:52-57.

17. Chiang TH, Chang CY, Huang KW, Liou JM, Lin JT, Wang HP: Jejunojejunal intussusception secondary to a jejuna lipoma in an adult. J Gastroenterol Hepatol 2006, 21:924-926.

doi:10.1186/1749-7922-7-28

Cite this article as: Mouagit et al: Adult intussusceptions caused by a lipoma in the jejunum: report of a case and review of the literature. World Journal of Emergency Surgery 2012 7:28. 